\title{
AS IMPLICAÇÕES POLÍTICAS DO REVISIONISMO CONTEMPORÂNEO
}

\author{
SENA JÚNIOR, Carlos Zacarias de; MELO, Demian Bezerra de; CALIL, \\ Gilberto Grassi (Orgs.). Contribuição à Crítica da Historiografia \\ Revisionista. Rio de Janeiro: Consequência, 2017.
}

Samuel Fernando da Silva Junior ${ }^{1}$

Dando continuidade ao projeto iniciado em 2014 com a publicação de $A$ miséria da historiografia, organizado por Demian Bezerra de Melo, (MELO, 2014), o livro ora resenhado objetiva escrutinar as implicações sociais da historiografia revisionista, especialmente, a brasileira. A hipótese geral que atravessa todos os artigos reunidos no livro vincula-se à posição de que os desdobramentos teóricos e historiográficos do revisionismo possuem relações diretas com as disputas políticas cotidianas.

Valendo-nos de um rápido exemplo sobre essas relações, o então presidente do Supremo Tribunal Federal (STF), Dias Toffoli, em ocasião do evento que tratava dos "30 anos da Constituição Federal de 1988", na Faculdade de Direito da USP, e após a polêmica nomeação do general da reserva Fernando Azevedo e Silva para assessorá-lo na presidência do STF, alegou que os desdobramentos político-militares de 1964 não são entendidos por ele como "golpe" ou "revolução", mas como "movimento de 1964", buscando responsabilizar tanto o suposto "radicalismo" de esquerda como o de direita como os verdadeiros motivadores da ação militar daquele período. Pata tais afirmações, dizia estar embasado na obra do historiador Daniel Aarão Reis Filho (TERRA, 2018), cujas produções mais emblemáticas e polêmicas estão circunscritas na temática revisionista. Muito embora o referido historiador da

\footnotetext{
${ }^{1}$ Mestre em História pela Universidade Estadual do Oeste do Paraná (UNIOESTE); Licenciado em História pela Universidade Federal de Mato Grosso do Sul (UFMS). E-mail: samuellfrnd@gmail.com.
} 
Universidade Federal Fluminense (UFF) tenha negado de forma veemente as relações entre a sua produção e a fala de Toffoli, o conjunto de sua obra retém significados que possibilitam interpretações análogas.

Nesse aspecto, as características que circunscrevem o revisionismo dizem respeito à suavização ou apagamento das lutas sociais; a objeção ou o esvaziamento teórico relacionado à existência das classes sociais; a reabilitação, dissimulada ou aberta, de interpretações conservadoras que buscam mistificar acontecimentos políticos traumáticos do ponto de vista social (não por mera casualidade, especialmente circunscritos no período da Guerra Fria, como golpes, revoluções, ditaduras, transições etc.); e aplacar as lutas sociais do passado ao sabor dos conflitos políticos do presente - seja no campo da memória, da história e da política. No debate brasileiro, o revisionismo é entendido, portanto, negativamente, pois está alicerçado em atributos conservadores, cujo intuito é reescrever a história do passado recente (especialmente aquela com irretorquíveis conflitos sociais), buscando pautar e embasar as disputas políticas no presente.

O livro estrutura-se em três eixos temáticos, os quais a produção revisionista possui maior interesse e robustez, são eles: "Ditadura e democracia", como artigos de Carlos Zacarias Sena Júnior, Gilberto Grassi Calil e Eurelino Coelho; "Revolução e contrarrevolução", com produções de Manuel Loff e Luciana Soutelo, Carla Luciana Silva, Tatiana da Silva Poggi de Figueiredo e Marcio Lauria Monteiro; e "Capitalismo e luta de classes", no qual se encontra textos de Demian Bezerra de Melo, Marco M. Pestana e Igor Gomes. O livro é prefaciado pela historiadora Virgínia Fontes e introduzido pelos organizadores.

Para iniciar o debate teórico e histórico acerca do revisionismo e da produção revisionista, os organizadores incluíram um capítulo do livro de Enzo Traverso, O Passado, modos de usar: história, memória e política, intitulado "Revisão e revisionismo", no qual Traverso se posiciona contra a ampla utilidade conceitual do "revisionismo" em razão de possuir um extenso espectro de significações. 
Apesar das questões levantadas por Traverso serem importantes para o debate, a existência de historiadores críticos ao revisionismo não se relaciona à intenção de criar uma "história oficial", mas de demonstrar que a produção teórica e historiográfica não está completamente isenta de determinações políticas. Ou seja, esses historiadores críticos ao revisionismo buscam evitar que a interpretação revisionista se transforme em perspectiva "normativa" da História. Para Traverso, não deveria existir historiadores revisionistas e historiadores críticos ao revisionismo, apenas historiadores críticos. Todavia, se na sociedade capitalista existem interesses de classe que são conflitantes e mesmo excludentes entre si, não seria de se estranhar que também no campo científico haja disputas políticas, disputas pela memória, pela história, pela verdade.

Carlos Zacarias em "A 'boa memória", utiliza-se do conceito "la buena memoria" do historiador catalão Ricard Vinyes para compreender a movimentação da produção revisionista brasileira a partir do final da década de 1980. O conceito nos remete à construção e à reabilitação de memórias sociais, entendidas por Vinyes como processos de privatização das formas de lembrar mediante a atuação estatal na extirpação memorialística dos espaços coletivos e no esvaziamento da carga política e afetiva da lembrança, conformando uma "economia memorial" com o intuito de consolidar um sistema administrativo de "bens morais e simbólicos, de controle de informações, datas, atos estatais [...]" etc. (p. 42).

Apropriando-se das análises de Vinyes sobre a imposição do "esquecimento" durante a anistia espanhola e o surgimento de uma série de leis relacionadas à memória em 1977, Carlos Zacarias demonstra como a historiografia revisionista, sobretudo a partir de 1980, reforçou alguns escritos memorialísticos de militares que buscavam uma reabilitação ou, conforme o conceito de Vinyes, uma "boa memória" do período ditatorial, como por exemplo a obra "Brasil sempre" do então sargento e ex-agente do DOI-CODI Marco Pollo Giordani (1986) (em oposição ao relatório "Brasil nunca mais") e o livro do ex-coronel Carlos Alberto Brilhante Ustra, "Rompendo o silêncio" 
(1985), configurando, portanto, uma "guerra pela memória", posto que a luta pela memória é uma das lutas pela hegemonia - no sentido gramsciano do termo.

Gilberto Calil, no capítulo "Elio Gaspari e a ditadura brasileira", demonstra como a produção do jornalista Elio Gaspari colaborou com as difusões de coloração revisionista em razão dos 40 anos do golpe. As principais hipóteses de Gaspari, ao longo de suas quatro primeiras obras da série, buscam avalizar aquilo que já vinha sendo produzido no final da década de 1980 e década de 1990 em torno da responsabilização da esquerda pelo Golpe de 1964, percebida também na fala de Toffoli em 2018, conforme mencionamos acima. Não obstante, incute uma visão positiva à ala "moderada" do exército (Castello Branco, Golbery do Couto e Silva e Ernesto Geisel) a partir da identificação equivocada entre distensão e democratização, uma deliberada e sistemática desqualificação da resistência armada à ditadura, e uma perspectiva legitimadora da transição conservadora. Conseguimos perceber, portanto, como a confecção de uma "boa memória", com a qual Zacarias trabalhou no primeiro capítulo, está impregnada na produção de Gaspari.

No terceiro capítulo, "Uma história no futuro do pretérito?", Eurelino Coelho mobiliza alguns dos elementos fundamentais da historiografia revisionista sobre o Golpe, a partir do livro de Jorge Ferreira e Angela de Castro Gomes, 1964: o golpe que derrubou um presidente, pôs fim ao regime democrático e instituiu a ditadura no Brasil, publicado em razão do cinquentenário de 1964. Uma das características do livro observada por Coelho é a de "uma história que poderia ter sido", cujo tempo verbal, o futuro do pretérito, é um tanto quanto estranho ao ofício do historiador: “o golpe de 1964 aconteceu, mas poderia não ter acontecido”. Seguindo esse caminho, Coelho explora as hipóteses contrafactuais levantadas no livro instruídas excessivamente pela imprevisibilidade histórica, cujo ponto nodal busca dar margem para o seguinte entendimento: "se" a esquerda, no contexto do golpe, "optasse" pela moderação e pela negociação, o golpe provavelmente não "teria" ocorrido. 
Essa argumentação viabiliza equívocos prejudiciais ao efetivo conhecimento histórico: ao estabelecer uma falsa simetria entre a esquerda e a direita, sendo o golpe, portanto, iminente nos dois lados; e ao sugerir a existência de uma extrema-direita disposta a negociar, mas que foi obrigada a dar um golpe (defensivo) em decorrência das trapaças da esquerda às regras do “jogo democrático”. Portanto, os apontamentos oportunizados por Coelho buscam demonstrar como a história aventada pelos revisionistas, nesse caso, por Ferreira e Gomes, só pode ser delimitada num tempo gramatical inexistente do ponto de vista da História.

Abrindo a segunda parte do livro, "Revolução e contrarrevolução", temos o capítulo de Manuel Loff e Luciana Soutelo, intitulado "A suspensão da ideia de Revolução na contemporaneidade. O caso português". Os autores demonstram como o ciclo revolucionário de 25 de abril de 1974 até 1976 sofreu uma série de releituras conservadoras, cujos objetivos estavam pautados em desabonar qualquer derivação política e social aglutinados na Revolução de Abril. Esses sucessivos aviltamentos à memória revolucionária também possuía um elo íntimo com a teoria do totalitarismo pujante na conjuntura da Guerra Fria, a qual, entre outros sentidos, conferiu (e confere) um fatalismo totalitário a qualquer ímpeto tipicamente revolucionário. No caso português, em ocasião do vigésimo aniversário da Revolução, o Primeiro-ministro Cavaco Silva (19851995), discursou acerca do legado de 1974, afirmando que "a revolução não instaurou a liberdade. Derrubou um regime autoritário, mas tentou erguer um regime totalitário em seu lugar” (p. 153).

O capítulo de Carla Silva, "Anticomunismo nas transições", elucida como as transições portuguesa e espanhola focalizadas pelas revistas Veja e IstoÉ estavam alheias à lógica dos "dois demônios" (ditadura e comunismo) criada artificialmente para embargar as lutas políticas dos períodos transicionais, lógica essa que tanto em Portugal como na Espanha favoreceu a consolidação de regimes conservadores com maior ou menor grau de continuidade com os regimes anteriores. Expõe também como essas duas revistas avaliam o percurso da distensão brasileira à luz das transições 
portuguesa e espanhola, principalmente no que se refere ao esquecimento, ao silêncio sobre o passado e à inculcação da "boa memória", mediada pela supressão de traumas e conflitos sociais.

Tatiana Silva Poggi de Figueiredo, no capítulo "Revisitando o fascismo", escrutina como a literatura revisionista se apropria de produções e interpretações surgidas ao longo da Guerra Fria, cujos debates estavam circunscritos em torno das ideias de revolução, totalitarismo e fascismo, com o propósito de reabilitar essas polêmicas nas produções contemporâneas. Para tanto, Poggi mobiliza uma série de autores que buscaram ressignificar o entendimento de revolução dentro de uma acepção conservadora, como François Furet e Alfred Corban, bem como o debate em torno do totalitarismo, utilizando Hannah Arendt e Raymond Aron, indo, por fim, ao encontro de uma historiografia mais recente (entre fins de 1970 e início de 1980), de corte "culturalista" (Emilio Gentile, George Mosse e Zeev Sternhell), a qual busca entender o fascismo dentro do campo cultural, sugerindo uma espécie de "normalização" do fascismo, pois concebe o regime fascista a partir de uma ampla base de consenso e aceitação social.

O capítulo "Revolução Russa e revisionismo historiográfico", de Marcio Lauria Monteiro, possui como problemática central a reabilitação da "sovietologia" dos anos 1930 e 1940 (composta pelos chamados cold warriors Richard Pipes, Robert Conquest etc.), por uma historiografia supostamente mais crítica surgida no final dos anos 1980, cujas figuras proeminentes são o historiador francês Sergio Ingerflom e o historiador estadunidense Peter Holquist. A hipótese de reabilitação contemporânea da "sovietologia" defendida por Monteiro é demonstrada pelo uso de determinados conceitos interpretativos situados no campo da história cultural, como "mentalidades" e "cultura política", os quais revalidam a antiga "tese da continuidade" entre Revolução de Outubro e stalinismo, justificando, tout court, os "horrores da ditadura de Stalin" pela atrasada "mentalidade" política russa, bem como pela existência de uma "cultura política" violenta na história da Rússia. 
Iniciando a terceira e última parte do livro, "Capitalismo e luta de classe", Demian Melo, no capítulo "O capitalismo e os historiadores", faz um considerável levantamento da historiografia "revisionista neoliberal" a qual embasa, política e teoricamente, o livro de Leandro Narloch, Guia politicamente incorreto da história do mundo. Melo elucida como o ambiente cultural brasileiro, por meio da obra de Narloch, está suscetível a uma reinterpretação do passado através de autores do "revisionismo neoliberal". Dentre outras alegações, tanto a historiografia neoliberal (principalmente, Ludwig von Mises, Friedrich Hayek, William Harold Hutt, John Harold Clapham etc.) quanto a produção de Narloch, buscam amenizar ou pintar com cores róseas o período da Revolução Industrial, preconizando, de forma apologética, a perspectiva do desenvolvimento econômico a despeito da "questão social”, ou seja, do emprego da mão de obra infantil e sua alta taxa de mortalidade, das extenuantes jornadas de trabalho etc. Para contraditar as apologias dos neoliberais sobre esse período, Demian retoma as análises de Marx, Engels e de historiadores como Hobsbawm e Thompson, a fim de evidenciar que o vasto material empírico utilizado por esses últimos autores contradiz frontalmente à perspectiva "revisionista neoliberal" sublinhada pelo diminuto recurso às fontes ou mesmo pela flagrante ausência delas.

Marco M. Pestana, em "O revisionismo a serviço da segregação urbana", examina o ciclo da "segregação social" aprofundado pelas remoções durante a década de 1960 no governo Carlos Lacerda (1960-1965) e com o advento do Golpe de 1964. Esse processo de remoção resultou na criação de conhecidas "comunidades" como, por exemplo, "Cidade de Deus", "Vila Aliança" e "Vila Kennedy", cujos índices de violência não foram atenuados, somente deslocados de um lugar para outro, geralmente, mais distante do centro e da zona mais nobre da cidade. Em vista desse e de inúmeros outros problemas sociais decorrentes das remoções, Marco Pestana analisa criticamente a obra de Maurício Dominguez Perez intitulada Lacerda na Guanabara: a reconstrução do Rio de Janeiro nos anos 1960 (2007), a qual procura recuperar a imagem do governo Lacerda e desenhar um quadro de resistência política praticamente 
inexistente entre os "favelados", mitigando os conflitos e mistificando o governo fluminense sob a égide da "eficiência" política e administrativa.

Para fechar a última parte do livro, o texto de Igor Gomes, "Culturalismo e sociedade 'de uma classe só' nos estudos do banditismo", demonstra como o culturalismo norteado pelo conceito de "cultura política" oferece um arsenal teórico bastante oportuno para o revisionismo. O autor verifica essa relação em seu estudo sobre o banditismo, cujo conceito "cultura da violência" enquanto modelo heurístico de entendimento da realidade social sertaneja, naturaliza e normaliza uma série de mecanismos de dominação e violência.

Acerca dessa temática tão polissêmica em suas significações, Gomes faz a crítica não somente à historiográfica culturalista que constrói um sertão sem política e atravessado exclusivamente pela violência enquanto "ethos", ou seja, como essência das relações sociais, mas também à interpretação social de Hobsbawm a qual cria um bandido "herói", o "banditismo social". Para Gomes, a constituição de uma realidade violenta no sertão foi permeada pela própria violência estatal/senhorial e pela miserabilidade generalizada que obrigava diversos grupos étnicos a constituírem variadas formas de resistência, no mais das vezes, em níveis pré-políticos.

Tecido esses rápidos comentários, percebemos como a corrente teórica revisionista possuí estreitas relações com os elementos políticos da luta de classes. Mais: visam normatizar o conhecimento social através de seus "postulados" que, na maioria das vezes, são menos científicos que ideológicos. A nosso ver, um dos principais méritos da corrente de historiadores críticos ao revisionismo, comentada aqui através do livro ora resenhado, reside justamente na demonstração dessa íntima relação entre a perspectiva teórica revisionista e os desdobramentos políticos contemporâneos. Não obstante, que teoria e política, para além de suas particulares mediações e momentos, possuem interações potencialmente implicantes na realidade social. Por isso, o revisionismo deve ser combatido honesta e abertamente, seja teoricamente, na batalha das ideias, seja politicamente, no campo da luta de classes. 


\section{Referências}

MELO, Demian B. de (org.). A miséria da historiografia: uma crítica ao revisionismo contemporâneo. Rio de Janeiro: Consequência, 2014.

SENA JÚNIOR, Carlos Zacarias de; MELO, Demian Bezerra de; CALIL, Gilberto Grassi (orgs.). Contribuição à crítica da historiografia revisionista. Rio de Janeiro: Consequência, 2017.

"Toffoli prefere chamar ditadura de 'movimento de 1964"'. Terra, 1 out de 2018.

Política.

Disponível

em:

https://www.terra.com.br/noticias/brasil/politica/toffoli-cita-historiador-e-dizque-brasil-teve-movimento-de64,fe414b7a4d4b262d7b4cffdaa46c9eadnupe15g4.html. Acessado em: 10/05/2020. 